\title{
Climate variability in Antarctica and the Southern Hemisphere over the past 2000 years
}

\author{
Elizabeth R. Thomas
}

\section{Cambridge, UK, 3-4 September 2018}

\section{CLIVASH2k is a PAGES $2 \mathrm{k}$ Network project} investigating Climate Variability in Antarctica and the Southern Hemisphere over the past 2000 years. Founded as part of the third phase of the PAGES $2 \mathrm{k}$ Network, it expands upon the efforts of the former regional groups which aimed to spatially reconstruct important state variables for the climate system. The focus of CLIVASH2k is understanding the drivers of climate variability, and incorporating climate reconstructions from Antarctica, the sub-Antarctic and the wider Southern Hemisphere to explore the regional to hemispheric teleconnections and associated modes of variability.

Forty researchers from more than 20 nations attended the two-day workshop hosted at the British Antarctic Survey. The workshop focused on three main scientific questions:

1) What is our current understanding of seaice variability?

2) What are the best proxies or regions for capturing changes in westerly winds?
3) How can paleoclimate data inform predictions of future climate change?

1) Sea ice plays a key role in modulating Antarctic climate, and the best archives of past sea ice arise from marine sediments and ice cores. New marine sea-ice proxies, such as highly branched isoprenoid biomarkers and the increased temporal resolution, are providing unprecedented records of sea-ice dynamics over the past 2000 years. Advanced analytical capabilities are also producing new ice-core proxies, such as organic compounds, sea salts and halogen species. The expanding network of marine records and coastal ice cores, including ice cores from the sub-Antarctic islands, is greatly improving our spatial coverage, especially in regions such as the Antarctic Peninsula and coastal Adelie Land. There is now a realistic potential to combine marine and ice-core proxies in these regions to produce multi-proxy reconstructions. However the spatial coverage in most other regions is still too poor to produce a comprehensive

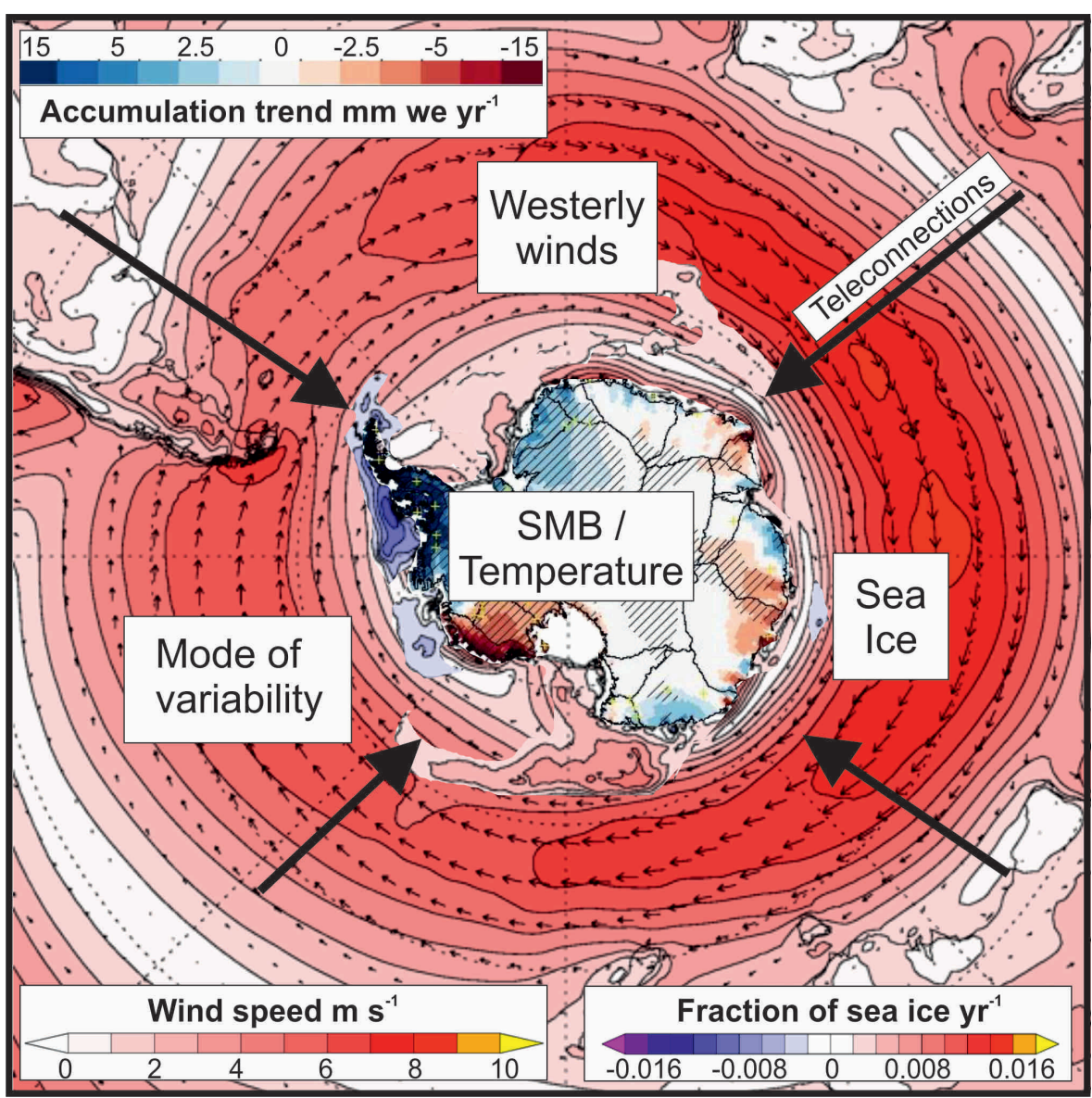

Figure 1: Drivers of climate variability in Antarctica and the Southern Hemisphere. The trend in Antarctic snowfall (Medley and Thomas 2019), the trend in Antarctic sea ice and the zonal wind anomalies from ERA-interim (19792010). sea-ice reconstruction for the past 2000 years.

2) Circumpolar westerly winds are a major driver of climate variability. The observed variability in Antarctic surface-mass balance during the 20th century (Fig. 1; Medley and Thomas 2019) is attributed to changes in westerly winds and the Southern Annular Mode (SAM). New paleoclimate reconstructions of the SAM and past westerly wind strength were presented, including Antarctica ice-core and terrestrial records (peat and moss banks), and lake sediments from the sub-Antarctic islands and South America. However, there is little consensus on what each of the proxies is telling us about westerly winds, with apparent differences in the interpretation of increased strength versus a shift in the location of the wind belt. The group agreed that defining the proxies from all archives would be beneficial and that we need to utilize the observational records and climate models to provide clarity in our interpretations.

3) An important aspect of CLIVASH2k is engaging with climate modelers to ensure that paleoclimate data can improve predictions of future climate change. Our workshop, supported by the SCAR scientific research program "Antarctica Climate Change in the 21st Century (AntClim21)" (scar.org/srp/antclim21), brought together climate modelers and paleoclimate specialists. We learned that many climate models struggle to capture the observed changes in key climate parameters, particularly sea ice. Paleoclimate data offers one solution to constrain the models, providing realistic boundary conditions; however, incorporating paleoclimate data is complex and difficult. Advances in data assimilation show promise, but a number of issues remain. The group identified the following recommendations for the paleoclimate community. The modelers require: 1) quantitative rather than qualitative data, 2) gridded data with good spatial coverage, 3) accurate error estimates, 4 ) a robust description of what the proxies mean, and 5) accurate dating.

The CLIVASH2K working group will hold its next meeting at INQUA in July 2019.

\section{AFFILIATION}

British Antarctic Survey, Cambridge, UK

\section{CONTACT}

Elizabeth Thomas: lith@bas.ac.uk

\section{REFERENCES}

Medley B, Thomas ER (2019) Nat Clim Change 9: 34-39 